\title{
ETHICS AND VALIDITY AS CORE ISSUES IN QUALITATIVE RESEARCH: A REVIEW PAPER
}

\author{
Zarina Waheed \\ Assistant Professor, \\ Department of Education, SBKWU, \\ Balochistan, Pakistan \\ Email: zarina.waheed@sbkwu.edu.pk
}

\author{
Abdul Nasir Kiazai \\ Assistant Professor, \\ Institute of Educational Research, University of Balochistan, \\ Balochistan, Pakistan \\ Email: mirnasir555@gmail.com \\ Waheed Bahadur \\ Scholar, \\ Department of Education, University of Karachi, \\ Sindh, Pakistan \\ Email: zehri_waheed@yahoo.com
}

\begin{abstract}
Qualitative research is criticized for having issues validity, reliability, and ethics. This review paper focuses on two core issues involved in qualitative research generally and in educational research more specifically. Firstly, this review sheds light on ethical issues involved in qualitative research. It also discusses issues of validity in qualitative research. In this study, narrative review method has been adopted. The secondary sources or previous research studies have been reviewed in order to suggest some research directions regarding the issues of validity and ethics in qualitative research. It was found that researcher plays a central role in assuring both validity and ethics in qualitative research. Researcher are recommended to have command on research techniques required for conducting qualitative studies. Moreover, researchers are recommended to adopt ethically appropriate practices by conducting honestly robust qualitative studies.
\end{abstract}

\section{KEYWORDS}

Qualitative research, Ethics, validity, educational research 


\section{INTRODUCTION}

In educational research, there are three paradigms as quantitative, qualitative and mixed method research. In mixed method research, both quantitative and qualitative approaches are adopted and it is considered as the most advanced and robust approach as it is based on triangulation and able to generate more valid and reliable results (Creswell, 2012). Similarly, quantitative research is one of the most used type of research in education and based on more standardized criterion and able to give generalizable results. Quantitative research also involves the application of the scientific methods to find out the solutions of educational problems (Mills \& Gay, 2009). The third approach in educational research is qualitative research. In qualitative research:

- Insights are gained from nonnumeric data,

- The phenomena are studied in its natural setting,

- Importance is giving to the beliefs, opinions, experiences and interpretations of the participants.

- Inductive approach

- Researcher is primary instrument

In qualitative research, it is assumed that reality in not a single and fixed phenomena, rather it is in a state of flux, contextual and multidimensional, therefore, it cannot be explored through quantitative approaches (Merriam, 2009). Qualitative studies, like quantitative studies do not focus on finding the cause and effect relationships between two or more variable but here the researchers analyze which events or practices lead to which consequences (Miles \& Huberman, 1994). "Qualitative researchers are interested in understanding how people interpret their experiences, how they construct their worlds, and what meaning they attribute to their experiences" (Merriam \& Tisdell, 2016, p. 6). From qualitative studies fruitful explanations can be derived and conceptual frameworks can be developed and revised (Miles \& Huberman, 1994). Most importantly, findings of qualitative studies are in the form of description of events, narratives and stories are more enjoyed by readers (Miles \& Huberman, 1994). Figure 1 gives a pictorial summary of some main characteristics and features of qualitative research.

Among, the three research paradigms qualitative research has been criticized for having issues of generalizability, validity, reliability, and ethics (Chesebro \& Borisoff, 2007; Pilnick \& Swift, 2010). According to Merriam and Tisdell (2016), the consideration towards uniqueness of ethical issues involved in qualitative research are in its infancy. Similarly, according to Cho and Trent (2006), there is insufficient research available to solve the problem of validity in qualitative research. There is also a critical need for empirical research to support methodological approaches to the evaluation of validity, and concerns of continual reevaluation of validity (Magasi et 
al., 2011). Thus, the aim of this paper is to review the relevant literature on the core issues in qualitative research. This study also aims at suggesting some techniques and methods to novice qualitative researchers to deal with issues of validity and ethics.

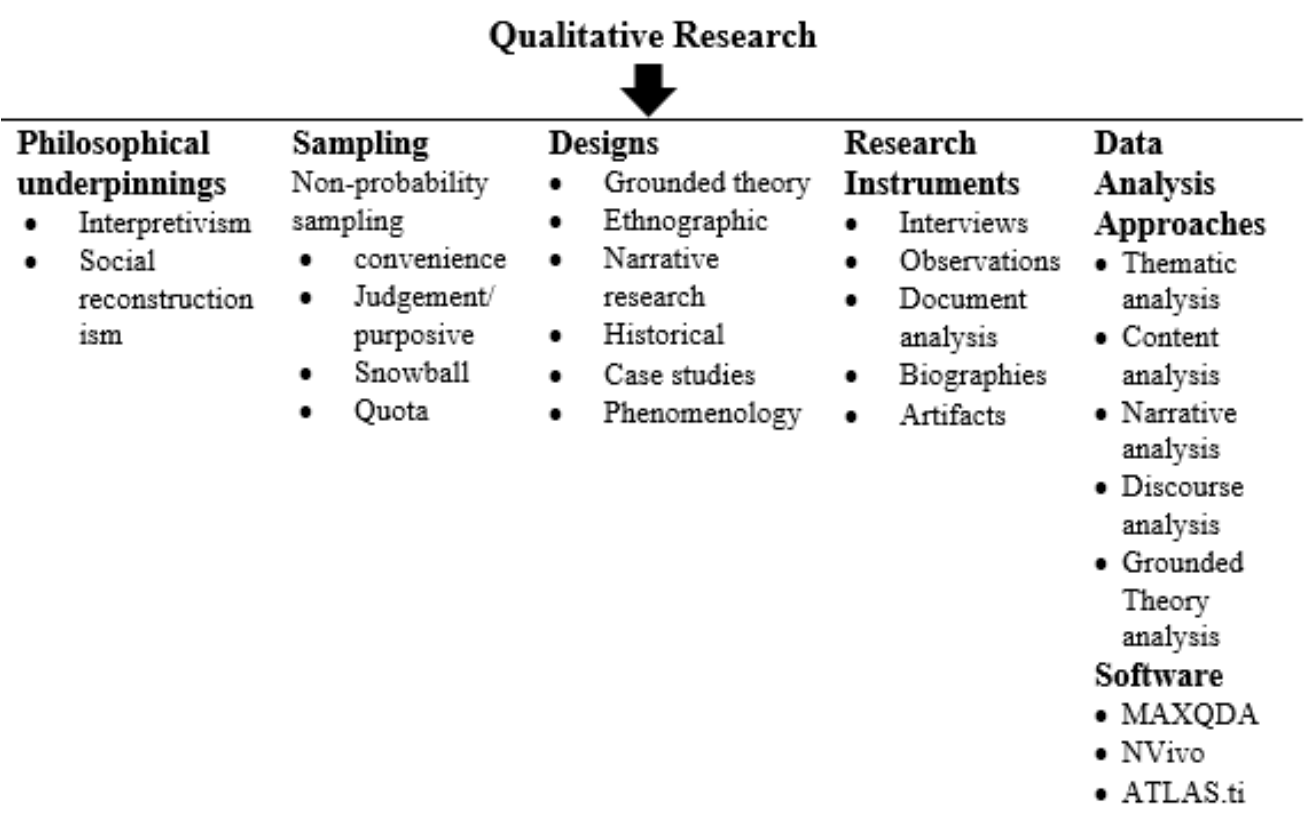

Figure 1. Some common characteristics of qualitative research

\section{RESEARCH METHODOLOGY}

The method used in this study is narrative overview. According to Green et al. (2006) a narrative overview is a comprehensively synthesizes previous published literature related to the topic under study. "Narrative overviews are useful educational articles since they pull many pieces of information together into a readable format" (Green et al., 2006, p. 103). Thus, secondary data is used in this study where the available literature related to qualitative research and validity and ethics in qualitative research are reviewed.

\section{Ethical Issues in Qualitative Research}

The issues of reliability and validity in qualitative research can be minimized if study is conducted in ethically appropriate manner (Merriam, 2009). Therefore, ethics is considered as the most critical issue in qualitative research. Firstly, unlike in quantitative research, the standardized criterion to avoid/minimize ethical problems are missing in qualitative research (Elliott \& Williams, 2006), because qualitative research involves in-depth study and ethics for its one type may not fulfill the ethical 
needs for its other types (Brownlow \& O'Dell, 2002; Zeni, 1998). In addition, Yardley (2000) claimed that the criteria (highlighting ethics) of judging quantitative reseach is well established while for qualitaive research it is in its infancy.

Secondly, as mentioned earlier in qulaitative research, researcher plays an important role and is directly involved in research and with human beings this relation may affect the personal and professional life of researcher as well as participant (Poole et al., 2004). Thirdly, sometimes researcher is practitioner too (e.g., teacher, counselor, doctor, nurse) and researcher unintentional involvement may cause ethical issues (Thompson \& Russo, 2012). Moreover, the subjective and unstructured nature of qualitative research create ethical issues too (Mishna et al., 2004; Pilnick \& Swift, 2010).

Kopelman (2004) concluded that qualitative research might have risks like embarrassment, discomfort, inconvenience, stigmatization, and may harm confidentiality, respect for person, privacy, nonmaleficence, social utility ,self esteem, justice and other psychological aspects. In addition to this, confidentiality, harm, sensitivity to context, commitment and rigour, transparency and coherence, impact and importance are also condiered as some ethical issues (Elliott \& Williams, 2006; Yardley, 2000). The condition becomes more critical when research is conducted with children due to protection of their rights, freedoms, safety, and dignity (Mishna et al., 2004). Besides, in different cultures settings, uniform ethical principle might not be effective as it may be applicable in one society and may not be in other or privacy and confidentiality might be changed from one society to an other, e.g in Bangladish you can ask names and phone numbers from any one and can use it for research purpose, they do not want to keep it confidential while same may not be in Eurpoean countries (Honan et al., 2012). To add in, Brownlow and O'Dell (2002) have clearly mentioned that there cannot be universally accepted guidelines for ethics in qualitative research.

Sensitive exploration by a qualitative reserachers and its maintains is critical issue as well. Sometime information is unintentionlly misused by the researcher and some researcher might force the respondant to give the information that a respondent may not want to disclouse (Thompson \& Russo, 2012). While sometimes the respondants spell out the thinkgs themselves during the interview that might be painful for them (West \& Byrne, 2009). Sometimes ressearcher may be forced from arm forces or agencies to share the evidances and sesnitive notes with them that can be against the ethics of research and reseacher might be helpless. Even few researchers like Richard Leo in 1995 whoes field notes were taken by the police and were subpoenaed, have requested that ethnographic researchers should be given freedom and rights not share what they have seen and heared (see, Lofland et al., 2006, p. 52). 
West and Byrne (2009) shared that some researchers might use painful treatments in counselling and psychotherapatic researches just to get funds from the doner especially from the companies which have made a drug and want it to be tested. So researchers' selfishness is also an issue that can influence ethics in research especially in qualitative research.

The above analysis shows that crtical issues may arise in qualitative research, therefore, novice researchers should be trained enough in delaing such issues as qualitative researchers.

\section{Validity in Qualitative Research:}

In qualitative research, quality due to validity has been a key issue (Meijer et al., 2002; Miles \& Huberman, 1994; Rolfe, 2006; Sinkovics et al., 2008). It is hard to define validity for qualitative researchers because most of the qualitative researcher fail to give an acceptable definition of validity or set of criteria like in quantitative research (Rolfe, 2006). For Secolsky et al. (2011), validity in qualitative research is related to interpretation of results while for Cho and Trent (2006) a study is said to be valid that accurately represents the reality or is the degree to which researchers' claims about knowledge corresponded. Validity is not a single term but contingent construct and researchers have used quality, rigor and trustworthiness as alternative terms for validity in qualitative research (Golafshani, 2003; Rolfe, 2006). Furthermore, the attempts to have generic acceptable criteria for the validity of qualitative research, like ethics, is impossible, because qualitative research does not have any unified body of theory and method and is an open question (Rolfe,2004).

The results obtained from the qualitative study may not be predictable because of the absence of standard of assuring validity. Additionally, validity like in quantitative reseach studies can not be obtained in qualiatative research due to the high level of subjectivity (Sinkovics et al., 2008). In addition to subjectivity, the problem of selection bias (not randomly or systematically selected), preference bias (more attention on a selected group of sample), detection bias (as researcher is instrument actually in qualitative research) also reduce validity in qualitative studies (Lewis, 2009). The qulalitative findings interms of making sense and crediblity to the readers may less be valid (Meijer et al., 2002).

Qualitative research have been criticized for not being able to deal with content validity (Brod et al., 2009). It has been criticized due to underrepresented or overrepresented content areas and abstract constructs (Landsheer \& Boeije, 2010). Sometimes researchers construct questions for research that are complex and there psychometric qualities can be uncertain and may result in problems of content validity in qualitative research (Landsheer \& Boeije, 2010). The data collected have a chance of 
inappropriate interpretation due to misunderstanding or oversimplification of data (Newton, 2012). Even sometimes participants expressions and gestures (important part of language and communication and sometime even change the meaning) can be overlooked. The problem of interpretation becomes worst when a qualitative study is conducted in cross-cultures. Thus, the role of researcher as interpreter may affects the finding of study and weaken the validity of research (Shimpuku \& Norr, 2012). Thus, qualitative research might have threats of validity due to interpetation and descripation of observation, manipulation of data, researcher's reflectivity and reactivity (Lewis, 2009). Qualitative researches are intervening agency between writer and reader a onesided approach to guarantee its validity constitutes a false dichotomy. Because, if researcher accepts the criterion of practitioner confidence as a means of judging methodological approaches, this involves rejection of judgement according to a methodology's own merits (Porter, 2007).

Qualitative research studies can't be replicated like quantitative research studies; then how can we measure its validity. Few researchers have said that triangulation method and respondent validation can be used as alternative methods in qualitative researches for validity (Pilnick \& Swift, 2010), While few has recommended to use reflexive research diaries in the end of each qualitative research (Rolfe, 2004) and validity checks. None of the suggested methods can be considered as alternative to validity because of unsustainability in replacement of its epistemological view (Porter, 2007).

Moreover, the purposed methods may have the problems due to human nature ( you cannot control all variables that may affect a person's nature) and research respondent's subjectivity can't be static (Koelsch, 2013), participants perception even can change during data collection (Murray 2003 cited in Koelsch,2013).Validity checks are not valid to be used in qualitative research because qualitative research is restricted to the constructivists and naturalistic only (Lewis, 2009). Sometimes researcher cannot control unanticipated involvement of others while taking interviews, here researcher comes between two fires (means if continues the interview it will be against ethics and validity, while stops interview or asks others to leave will be against social and moral ethics (Honan et al., 2012) . thus, validity is also a major challenge in qualitative research.

\section{Overcoming Validity Issues in Qualitative Research}

The previous sections show that qualitative research faces two main issues of validity and ethics. However, qualitative researchers have proposed various strategies to enhance the validity of qualitative research and ensure ethics. According to Merriam, (2009), the concepts of reliability, validity, generalizability in qualitative research are defiantly different from that of the quantitative research therefore need to be tackled differently. She has used more qualitative terms as transferability, credibility, 
consistency as alternative terms for qualitative external validity, internal validity, and reliability. Figure 2 presents the procedures used to enhance external validity, internal validity reliability and ethics in qualitative research (Merriam, 2009; Merriam \& Tisdell, 2016).

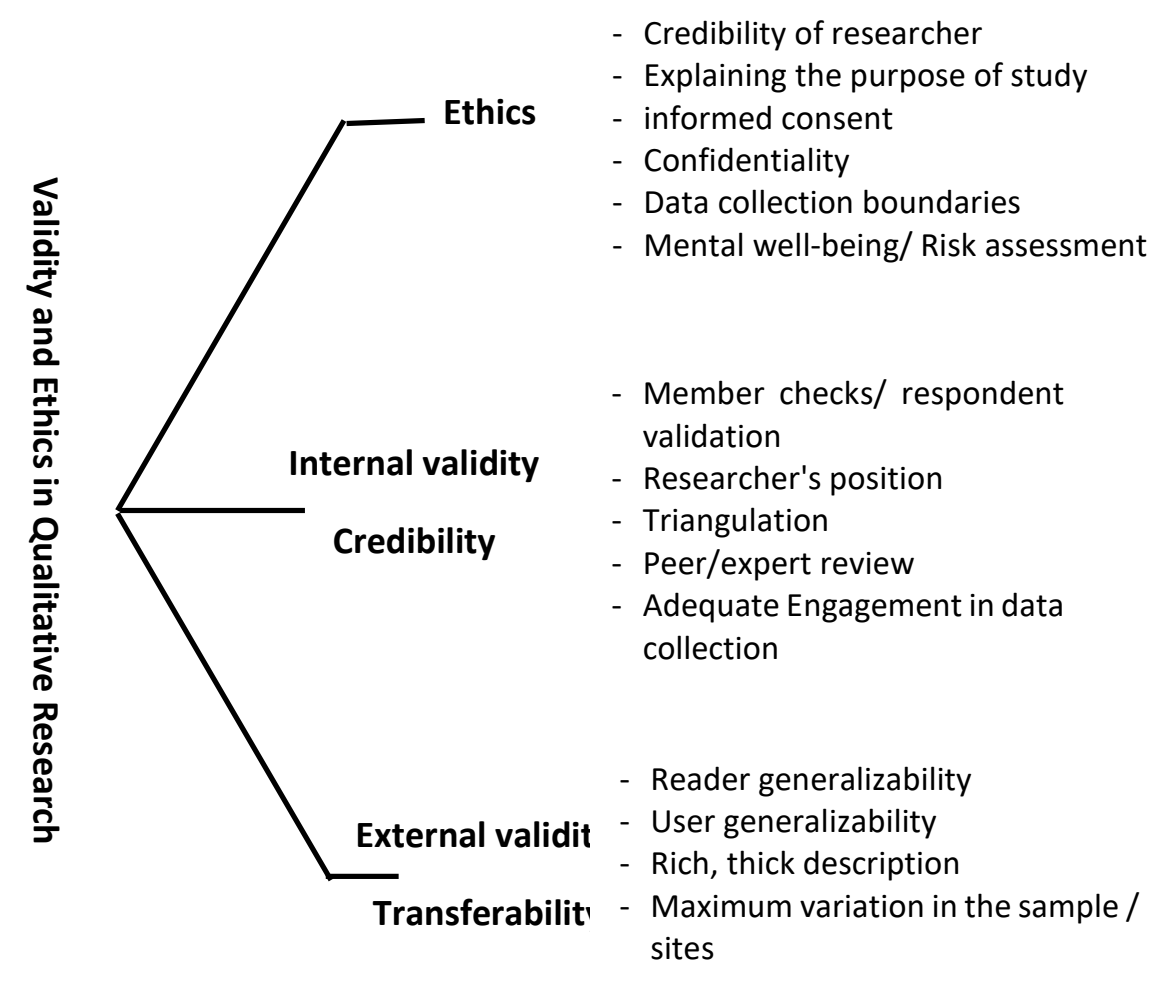

Figure 2. Some Suggested Strategies to Enhance Validity and Ethics in Qualitative Research (Source: Merriam \& Tisdell, 2016; Merriam, 2009).

External validity refers to the applicability, transferability, generalizability or fittingness of results to other similar situations while internal validity stands for analyzing how do findings make sense, do the findings match the reality, and are findings credible (Merriam, 2009; Miles \& Huberman, 1994). Qualitative studies are naturalistic therefore they require different methods to deal with validity issues. "This does not mean that concepts of validity are inapplicable or nonsensical, but it does mean that we have to re-appraise their meaning and use" (Norris, 1997, p 172). Merriam (2009) suggest different method and procedures for enhancing internal and external validity of the findings. He suggested that with triangulation, member check, adequate engagement in data collection, peer review, and researchers' position the internal validity of the qualitative research increases. Triangulation stands for using 
multiple methods or data collection tools, investigators, data source and theories to validate emerging findings. In multiple data collection tools also called as multiple methods, the researchers are suggested to adopt from two to four instruments to collect data in order to reach reality through comparing and contrasting from the data collected with the help of different tools like interviews, documents, observations (see, Meijer et al., 2002). In multiple investigator, more than one investigators study the same phenomena by having their own sets of data for analysis or expertise (see, Brod et al., 2009). While in data source triangulation, the same phenomena is investigated from multiple participation to get valid data (see, Waheed et al., 2018). Lastly, in theory triangulation, "different theories or hypotheses can assist the researcher in supporting or refuting findings" (Carter et al., 2014).

The member check is process where the researchers takes back field notes, interview transcripts or preliminary analysis back to the participate to review and approve if the words and interpretations are correct. This process is also called respondent validation and accurse throughout the study (Cho \& Trent, 2006; Merriam, 2009). The adequate engagement in data collection means that the researcher should engage himself/ herself in data collection by remaining close to participants' understanding for a particular phenomenon at the point of saturation. Researchers' position, is a process where researcher as main instrument in the study explains his/her biases, dispositions, and assumptions regarding the study (Merriam, 2009). The last method, peer review, is a process where external reviewers provide the evidences of accuracy or validation (Creswell, 2012). Critical friends and colleagues can help the researcher explore their preferences for certain kinds of evidence, interpretations and explanations and consider alternatives, locate blind spots and omissions, assess sampling procedures to highlight selection biases, examine judgements and make the processes of research more public (Norris, 1997, pp 174-175).

For enhancing external validity, user generalizability, reader generalizability, rich thick discretion, and maximum variation in sample are the methods proposed by Merriam (2009). The reader and user generalizability mean that the applicability of the findings depends on the reader and user. If a reader or a user, in a particular situation finds the findings useful for himself/herself, the findings are said to applicable for $\mathrm{him} / \mathrm{her}$. The second type, rich thick description means the researcher need to provide a rich and thick description of the participants and the settings where the research has been conducted and findings of the study. In this regard, the researcher is suggested to give adequate and relevant quotations from the interview, field notes, and documents to support the analysis and findings. Lastly, Merriam (2009) suggests to give careful consideration to the sample selection in qualitative research. In this regard, she suggests to bring maximum variation in selection of sites and participants in order to enhance transferability or external validity. 
Thus, it is suggested to novice researchers to use member check, expert or peer review, rich thick description, adequate sample selection and data collection, researchers' position and triangulation in order to enhance the validity of their qualitative research findings.

\section{Overcoming Ethics Issues in Qualitative Research}

A researcher needs to demonstrate ethically appropriate practices and strategies in all steps and types of research. According to Creswell (2012), ethics in educational research are not simply following some set standards and guidelines rather it is based on ethically sound practices in all steps of conducting and disseminating research. Like validity, dealing with ethics in qualitative research has also remained a challenge for researchers. In qualitative research, the credibility of the researcher is the most important consideration. As qualitative research is naturalistic in nature and it requires researcher full involvement in process of research and with participants. According to Norris (1997), a researcher should be honest and fair in qualitative research in order to enhance its quality. In addition to this, to do justice with qualitative research the researcher should have relevant training, profound experience and intellectual rigor (Merriam \& Tisdell, 2016). The researchers should also not only ensure the protection and rights of the participants but also report these all consideration in detail. In addition, to researchers own sensitivity and values, methodological ethical practices should be strictly be adopted. The sample selections, data collection, during data collection, data analysis, reporting, all steps ethics should be ensured. Following are some strategies suggested by the researchers to ensure ethical practices in qualitative research (Burgess, 2005; Merriam \& Tisdell, 2016; Patton, 2002):

1. A detailed informed consent form should be used with clear description for aims and procedures of research, expectations from the participants, privacy, rights and confidentiality, the role of researcher, benefits that the participants can get, and some sample questions.

2. If already developed ethical standards are available, the researchers should follow them strictly. In some countries, like the case is in Pakistan, such ethical guidelines are not available in some institutions. In this regard, university research committee and especially the supervisors should guide their students.

3. The researchers should be trained enough (by the experts or through extensive reading) in conducting qualitative studies to get themselves equipped with ability to deal with the issues of privacy and confidentiality as well as asking sensitive questions.

4. A relation of respect should be developed between researcher and researched.

5. Researcher should adopt ethically appropriate practices by conducting honestly robust studies. Fakeness in data, fakeness in interpretations, fakeness in analysis, and fakeness in reporting should strictly be avoided and prohibited. 
6. The researcher should define the data collection boundaries before data collection and participants should clearly be communicated data collection boundaries.

7. The researcher should assess how the process of interviews may affect their mental wellbeing and also risk the participants. For example, during the interview the participants may share some stressful experiences.

\section{CONCLUSION}

This review paper highlighted the issues of validity and ethics in qualitative research. It was found that qualitative research is considered sensitive in terms of validity and ethics. However, researchers have suggested transferability, credibility or trustworthiness as alternative methods to answer the questions of validity. Moreover, researcher plays a central role in assuring both validity and ethics in qualitative research therefore a researcher should have all required competencies for conducting qualitative studies. There are some important and preferred books of qualitative research (e.g., Corbin \& Strauss, 2008; Merriam \& Tisdell, 2016; Miles \& Huberman, 1994; Patton, 2002; Yin, 2009), the novice researchers are suggested to read these books thoroughly in order to understand and learn all methodological concepts and steps clearly.

\section{RECOMENDATIONS}

1. It is recommended that researcher should have command on research techniques required for conducting qualitative studies.

2. Researchers are recommended to adopt ethically appropriate practices by conducting honestly robust qualitative studies.

3. It must be included in research courses.

\section{REFERENCES}

Brod, M., Tesler, L. E., \& Christensen, T. L. (2009). Qualitative research and content validity : developing best practices based on science and experience. Qualitative Life Research, 18, 1263-1278. https://doi.org/10.1007/s11136-009-9540-9

Brownlow, C., \& O'Dell, L. (2002). Ethical Issues for Qualitative Research in Online Communities. Disability and Society, 17(6), 685-694. https://doi.org/10.1080/0968759022000010452

Burgess, R. G. (2005). Grey Areas: Ethical Dilemmas in Educational Ethnography. In R. G.Burgess (Ed.), The Ethics of Educational Research (8th ed., pp. 1-212). The Falmer Press.

Carter, N., Bryant-lukosius, D., Dicenso, A., Blythe, J., \& Neville, A. J. (2014). The Use of Triangulation in Qualitative Research. Methods \& Meanings, 41(5), 545-547. https://doi.org/10.1188/14.ONF.545-547 
Chesebro, J. W., \& Borisoff, D. J. (2007). What Makes Qualitative Research Qualitative? Qualitative Research Reports in Communication Vol., 8(1), 3-14. https://doi.org/10.1080/17459430701617846

Cho, J., \& Trent, A. (2006). Validity in qualitative research revisited. Qualitative Research, 6(3), 319-340. https://doi.org/10.1177/1468794106065006

Corbin, J., \& Strauss, A. (2008). Basics of qualitative research: Techniques and procedures for developing grounded theory. (3rd ed.). SAGE.

Creswell, J. W. (2012). Educational research:Planning, conducting and evaluating quantitative and qualitative research (4th ed.). Pearson Education Inc.

Elliott, M. S., \& Williams, D. I. (2006). Paradoxes of qualitative research. Counselling and Psychotheraphy Research, 1(3), 181-183. https://doi.org/https://doi.org/10.1080/14733140112331385050

Golafshani, N. (2003). Understanding Reliability and Validity in Qualitative Research. The Qualitative Report, 8(4), 597-607.

Green, B. N., Johnson, C. D., \& Adams, A. (2006). Writing narrative literature reviews for peer-reviewed journals: secrets of the trade. Ournal of Chiropractic Medicine, 5(3), 101117. https://doi.org/10.1162/ling_a_00246

Honan, E., Hamid, M. O., Alhamdan, B., Phommalangsy, P., \& Lingard, B. (2012). Ethical issues in cross-cultural research. International Journal of Research \& Method in Education, 1-14. https://doi.org/10.1080/1743727X.2012.705275

Koelsch, L. E. (2013). Reconceptualizing the Member Check Interview. International Journal of Qualitative Methods, 12, 168-179. https://doi.org/10.1177/160940691301200105

Kopelman, L. M. (2004). Minimal Risk as an International Ethical Standard in Research. Journal of Medicine and Philosophy, 29(3), 351-378.

Landsheer, J. A., \& Boeije, H. R. (2010). In search of content validity: facet analysis as a qualitative method to improve questionnaire design. Qual Quant, 44, 59-69. https://doi.org/10.1007/s11135-008-9179-6

Lewis, J. (2009). Redefining Qualitative Methods: Believability in the Fifth Moment. International Journal of Qualitative Methods, 8(2), 1-14.

Lofland, J., Snow, D., Anderson, L., \& Lofland, L. H. (2006). Analyzing social settins: A guide to qualitative observation and analysis (4th ed.). Wadsworth Publishing Company.

Magasi, S., Ryan, G., Revicki, D., Lenderking, W., Hays, R. D., Brod, M., Snyder, C., Boers, M., \& Cella, D. (2011). Content validity of patient-reported outcome measures: Perspectives from a PROMIS meeting. Quality of Life Research, 21, 739-746. https://doi.org/10.1007/s11136-011-9990-8

Meijer, P. C., Verloop, N., \& Beijaard, D. (2002). Multi-Method Triangulation in a Qualitative Study on Teachers ' Practical Knowledge: An Attempt to Increase Internal Validity Multi-Method Triangulation in a Qualitative Study on Teachers' Practical Knowledge : An Attempt to Increase Internal Validity. Quality \& Quantity, 36, 145-167. https://doi.org/10.1023/A

Merriam, S. B. (2009). Qualitative research: A guide to design and implementation. JosseyBass.

Merriam, S. B., \& Tisdell, E. J. (2016). Quallitative Research: A Guide to Design and Implementation (Fourth Edi). Jossey-Bass.

Miles, M., \& Huberman, A. M. (1994). Qualitative data analysis:An expanded sourcebook 
(2nd ed.). SAGE.

Mills, G. E., \& Gay, L. R. (2009). Educational Research: Competencies for analysis and application. In Educational Research (12th ed.). Pearson Education Inc.

Mishna, F., Antle, B. J., \& Regehr, C. (2004). Tapping the perspectives of children: Emerging ethical issues in qualitative research. Qualitative Social Work, 3(4), 449-468.

Newton, P. E. (2012). Clarifying the consensus definition of validity. Measurement: Interdisciplinary Research \& Perspective, 10(1-2), 1-29.

Norris, N. (1997). Error , bias and validity in qualitative research. Educational Action Research, 5(1), 172-176. https://doi.org/10.1080/09650799700200020

Patton, M. . (2002). Qualitative Research \& Evaluation Methods (3rd ed.). SAGE Publications.

Pilnick, A., \& Swift, J. A. (2010). Qualitative research in nutrition and dietetics : assessing quality. Journal of Human Nutrition and Dietetics, 24, 209-214. https://doi.org/10.1111/j.1365-277X.2010.01120.x

Poole, H., Giles, D. C., \& Moore, K. (2004). Researching sexuality and sexual issues: implications for the researcher? Sexual and Relationship Therapy, 19(1), 79-86.

Porter, S. (2007). Validity, trustworthiness and rigour: reasserting realism in qualitative research. Journal of Advanced Nursing, 60(1), 79-86. https://doi.org/10.1111/j.13652648.2007.04360.x

Rolfe, G. (2006). Validity, trustworthiness and rigour: quality and the idea of qualitative research. Methodological Isues in Nursing Research, 304-310.

Secolsky, C., Wentland, E., \& Denison, B. (2011). The need for documenting validation transactions: A qualitative component of the testing validation process. Quality and Quantity, 45, 1303-1311. https://doi.org/10.1007/s11135-011-9457-6

Shimpuku, Y., \& Norr, K. F. (2012). Working with interpreters in cross-cultural qualitative research in the context of a developing country: systematic literature review. Journal of Advanced Nursing, 68(8), 1692-1706.

Sinkovics, R. R., Penz, E., \& Ghauri, P. N. (2008). Enhancing the Trustworthiness of Qualitative Research in International Business. Management IIternational Review, 48(June), 689-714. https://doi.org/10.1007/s11575-008-0103-z

Thompson, A. R., \& Russo, K. (2012). Ethical dilemmas for clinical psychologists in conducting qualitative research. Qualitative Research in Psychology, 9(1), 32-46.

Waheed, Z., Hussin, S., \& Bin Megat Daud, M. A. K. (2018). The best practices for school transformation: a multiple-case study. Journal of Educational Administration, 56(1). https://doi.org/10.1108/JEA-11-2016-0136

West, W., \& Byrne, J. (2009). Some ethical concerns about counselling research. Counselling Psychology Quarterly, 22(3), 309-318.

Yardley, L. (2000). Dilemmas in qualitative health research. Psychology and Health, 15(2), 215-228.

Yin, R. K. (2009). Case study research: Design and methods (4th ed.). SAGE.

Zeni, J. (1998). A guide to ethical issues and action research. Educational Action Research, 6(1). https://doi.org/10.1080/09650799800200053 